\title{
Sobre a emergência e a expansão dos Estudos Culturais em educação no Brasil
}

\author{
On the emergence and expansion of Cultural Studies in education in Brazil
}

\author{
Sobre la emergencia y la expansión de los Estudios Culturales en educación en Brasil
}

\author{
MARIA LÚCIA CASTAGNA WORTMANN* \\ MARISA VORRABER COSTA** \\ ROSA MARIA HESSEL SILVEIRA***
}

\begin{abstract}
RESUMO - O artigo examina a emergência/invenção da articulação entre Educação e Estudos Culturais no Brasil, bem como as principais tendências dos estudos realizados na interface desses campos nos últimos dezoito anos (1996-2014). Aborda direcionamentos de dissertações e teses produzidas em dois programas de pós-graduação em educação que adotaram tal perspectiva. Apontam-se três tendências principais: a) ressignificação, mediante novas lentes teóricas, de questões, discursos e artefatos tradicionalmente relacionados ao campo pedagógico; b) análise da multiplicidade de pedagogias em operação nos diversificados espaços culturais contemporâneos; c) análise de processos implicados em questões de identidade-diferença. São também apontados e discutidos conceitos e autores que têm se mostrado produtivos, assim como alguns focos e questões preferenciais dos trabalhos.

Palavras-chave - Estudos Culturais em educação. Pedagogias culturais. Identidade-diferença. Cultura e educação. História da educação.
\end{abstract}

\begin{abstract}
This paper examines the emergence/invention of the articulation between Education and Cultural Studies in Brazil, as well as the main tendencies of the studies focusing the interface of these fields in the last eighteen years (1996-2014). It addresses dissertations and theses produced in two postgraduate courses in education using this perspective. There are three major tendencies: (i) resignification of issues, discourses and artefacts traditionally related to the pedagogical field through fresh theoretical lens; (ii) analysis of multiple pedagogies that work in different contemporary cultural contexts; and (iii) analysis of processes associated to issues of identity/difference. In addition, the paper also addresses productive concepts and authors, as well as their focuses and issues.

Keywords - Cultural Studies in education. Cultural pedagogies. Identity/difference. Culture and education. History of education.

RESUMEN - El artículo examina la emergencia/invención de la articulación entre Educación y Estudios Culturales en Brasil, bien como las principales tendencias de los estudios realizados en la interfaz de esos campos en los últimos dieciocho años (1996-2014). Aborda direccionamientos de disertaciones y tesis producidas en dos programas de posgrado en Educación que adptaron tal perspectiva. Se señalan tres tendencias principales: a) resignificación, mediante nuevos lentes teóricos, de cuestiones, discursos y artefactos tradicionalmente relacionados al campo pedagógico; b) análisis de la multiplicidad de pedagogías en operación en los diversificados espacios culturales contemporáneos; c) análisis de procesos implicados en cuestiones de identidad-diferencia. También son señalados y discutidos conceptos y autores que se han mostrado productivos, así como algunos focos y cuestiones preferenciales de los trabajos.
\end{abstract}

Palabras clave - Estudios Culturales en educación. Pedagogías culturales. Identidad-diferencia. Cultura y educación. Historia de la educación.

\footnotetext{
*Doutora em Educação pela Universidade Federal do Rio Grande do Sul (Porto Alegre, RS, Brasil) e professora na Universidade Luterana do Brasil (Canoas, RS, Brasil).E-mail: <wortmann@terra.com.br>.

**Doutora em Ciências Humanas pela Universidade Federal do Rio Grande do Sul (Porto Alegre, RS, Brasil) e Professora na Universidade Luterana do Brasil (Canoas, RS, Brasil).E-mail: <vorrabercosta@gmail.com>.

*** Doutora em Educação pela Universidade Federal do Rio Grande do Sul (Porto Alegre, RS, Brasil) e professora na Universidade Federal do Rio Grande do Sul (Porto Alegre, RS, Brasil).E-mail: <rosamhs@terra.com.br>.
} 


\section{INTRODUÇÃO}

A entrada dos Estudos Culturais no campo da Educação no Brasil data de meados dos anos 1990. Um acontecimento decisivo para o estabelecimento de algumas das vinculações que hoje temos entre Estudos Culturais e educação teve lugar no final de 1996, quando, na reestruturação do Programa de Pós-Graduação em Educação da Universidade Federal do Rio Grande do Sul (PPGEDU/UFRGS), ${ }^{1}$ foram introduzidas linhas de pesquisa, em substituição às anteriores áreas de concentração, entre as quais a linha "Estudos Culturais em Educação". Passados cerca de 18 anos da implantação dessa proposta, buscamos, neste texto, indicar algumas contingências que permitiram a instauração de tal articulação e, especialmente, avaliar a produtividade de tê-la empreendido, em função do considerável número de praticantes $^{2}$ que se têm comprometido com essa peculiar abordagem dos processos educativos, não apenas no contexto do Programa de Pós-Graduação acima referido, mas, também, em outras universidades brasileiras.

Pretendemos, assim, retomar aspectos que caracterizaram essa movimentação, bem como apontar tendências que marcaram tal encontro, buscando registrar e discutir algumas das direções seguidas pelos estudos conduzidos na interface desses campos. Destacamos a importância desse empreendimento, lembrando a posição de Lawrence Grossberg (2012), que nos convoca a promover análises culturais que exercitem o espírito crítico e mobilizem "ferramentas" que as atualizem frente aos novos territórios de investigação engendrados nas sociedades contemporâneas. Como salientou Grossberg (2008), a prática da autorreflexão se faz necessária quando se pretende dar respostas a certas exigências e restrições que passam a ser associadas a um determinado campo de estudos, bem como quando se busca indicar possibilidades por esse oferecidas, dimensão que, na situação aqui abordada, envolverá a discussão de ações e práticas pedagógicas, por um lado, e, por outro, de questões e categorias analíticas que consideramos estarem posicionadas na intersecção da Educação com os estudos culturais. Lembramos ser essa uma prática avaliativa frequente em textos conduzidos a partir dos estudos culturais, tais como os de Nelson, Treichler, Grossberg (1995), Ferguson e Golding (1997), Johnson (1999), Schulman (1999), Hall (2003), Costa, Silveira, Sommer (2003), Mattelart e Neveu (2004), Grossberg (2008, 2012). Discutimos, então, algumas propostas assumidas nesta prática articulatória ${ }^{3}$ que emergiu, inicialmente, no espaço teórico-político da Faculdade de Educação da UFRGS, em um momento em que alguns de seus docentes ansiavam promover a desarticulação do campo educativo das conexões que o atrelavam fortemente ao pensamento freiriano e a estudos centrados na psicologia genética piagetiana. ${ }^{4}$ É esse momento e os primeiros desdobramentos das ações então realizadas que focalizaremos na próxima seção.

\section{EMERGÊNCIA E EXPANSÃO DA ARTICULAÇÃo ENTRE ESTUdOS CULTURAIS E EDUCAÇÃo}

Indicamos, inicialmente e de forma breve, algumas situações que parecem ter se alinhado ao citado desejo de desconectar o campo educativo brasileiro das vertentes dominantes nos anos 90. Entre essas, está o seminário intitulado "Escola Básica na Virada do Século: cultura, política e currículo", realizado no ano de 1995 para comemorar os 25 anos da Faculdade de Educação da UFRGS, da qual era diretora a professora Maria Isabel Bujes. Em depoimento pessoal às autoras deste texto, Bujes destacou terem sido focalizados, naquele evento, "os desafios que a escola básica representava para um país que, como o Brasil, se caracterizava pelas desigualdades sociais, econômicas e culturais e pelos índices pífios de sucesso escolar", e terem dele participado colegas da própria Faculdade e acadêmicos/as de renome internacional, 5 a maior parte deles identificada com reflexões que questionavam o arcabouço teórico que sustentara a produção da pedagogia moderna e da teoria educacional crítica. Como também destacou Bujes, enfatizou-se, naquele seminário, serem a educação, a pedagogia e a escola básica campos problemáticos que mereceriam ser escrutinados a partir de referenciais capazes de romper com as teorizações canônicas vigentes. Igualmente representativos do clima que se vivia na Faculdade de Educação da UFRGS, naquela época, ${ }^{6}$ são os seminários curriculares conduzidos pelo professor Tomaz Tadeu da Silva, ${ }^{7}$ no PPGEDU, nos quais foram tecidas aproximações tanto com as ideias pós-estruturalistas quanto com os estudos culturais. ${ }^{8}$ Datam dessa época os livros $O$ sujeito da educação estudos foucaultianos, organizado por Silva (1994) e Crítica pós-estruturalista e Educação, organizado pelo também professor da Faculdade de Educação da UFRGS, Alfredo Veiga-Neto (1995), que reuniu estudos realizados nessa unidade universitária sobre temáticas como teoria educacional crítica, virada linguística e muitas outras relacionadas ao pensamento pós-estruturalista em suas conexões com o campo da educação, discutidas sob a inspiração de Jacques Derrida, Michel Foucault, Jacques Lacan, Jean-François Lyotard, Richard Rorty, Gianni Vattimo, Thomas Popkewitz e outros de linhas de pensamento afins.

Entretanto, o livro que marcou decisivamente a aproximação da educação aos EC no âmbito do PPGEdu 
da UFRGS foi Alienígenas na sala de aula - uma introdução aos Estudos Culturais em educação, ${ }^{9}$ no qual estão traduzidos textos originalmente publicados no livro Cultural studies, organizado por Grossberg, Nelson e Treichler (1992). Nele constam, além do texto introdutório, que apresenta de forma extensa o campo dos EC pelos organizadores do livro original, ${ }^{10}$ estudos desenvolvidos pela britânica Angela McRobbie ${ }^{11}$ e pelos estadunidenses Douglas Kellner e Henry Giroux, autores que continuam sendo muito citados em análises culturais.

É possível dizer, assim, que, a partir da criação da linha de pesquisa "Estudos Culturais em Educação" no PPGEDU da UFRGS, vertentes teóricas pouco invocadas no ambiente universitário gaúcho, à época, foram colocadas em destaque, tanto através de traduções de textos de autores ingleses vinculados ao Centre for Contemporary Cultural Studies, ${ }^{12}$ tais como Stuart Hall, Paul Willis, Paul Du Gay e Angela McRobbie, e norte-americanos, que consideramos já ser uma segunda geração de estudiosos desse campo, como Henry Giroux, Douglas Kellner e Shirley Steinberg, quanto de pesquisas (incluindo-se entre essas dissertações de mestrado e teses de doutorado), que vieram à luz principalmente sob a forma de livros e de artigos publicados em periódicos nacionais e anais de congressos. Esses últimos trabalhos talvez possam ser já considerados como uma terceira geração de estudos, classificação que demandaria exame mais detido, o qual foge ao âmbito do presente texto.

Nos dias atuais, o campo dos EC encontra-se institucionalizado, ${ }^{13}$ o mesmo sucedendo com os estudos em Educação que a ele se articulam, sendo exemplos disso, além do fortalecimento da Linha de Pesquisa Estudos Culturais em Educação da Universidade Federal do Rio Grande do Sul, que já formou 124 mestres e 79 doutores, ${ }^{14}$ a criação do curso de Mestrado em Educação da ULBRA (2002), com área de concentração nos Estudos Culturais, ${ }^{15}$ e da Linha de Pesquisa em Estudos Culturais da Educação no Programa de Pós-Graduação em Educação na Universidade Federal da Paraíba (2007). Entretanto, apesar dessa já considerável expansão de estudos acadêmicos, o campo ainda não figura na tabela de áreas de classificação do conhecimento destacadas pelo Conselho Nacional de Desenvolvimento Científico e Tecnológico (CNPq) na área de Educação. ${ }^{16}$

Cabe lembrar que um dos debates no campo dos EC são as consequências da sua institucionalização, ainda que ela se tenha mostrado como uma condição necessária à sua expansão no mundo acadêmico. Registramos, por outro lado, que há, nesse projeto articulatório, uma inegável influência dos estudos ingleses e norteamericanos, especialmente, no caso desses últimos, dos estudos que focalizam a noção de pedagogias culturais, como adiante veremos. Nos casos da UFRGS e da ULBRA, destacamos, também, a aproximação feita ao pensamento de Michel Foucault e outros pensadores contemporâneos, tais como Zygmunt Bauman, Richard Sennet, Jacques Derrida, Gilles Deleuze, Antonio Negri, Gilles Lipovetsky, Néstor García Canclini, Jesús Martín Barbero, Beatriz Sarlo, Jorge Larrosa, David Harvey, Fredric Jameson e muitos outros com direcionamentos teóricos aproximados.

Ainda nos interessa indicar, introdutoriamente, que a articulação da Educação com os EC tem sido realizada com certa cautela, não estando imune a críticas. Entre essas há aquelas que consideram ter decorrido dessa opção um afastamento de questões mais pertinentes a ações educativas, especialmente das que dizem respeito a proposições ou ao estabelecimento de diretrizes sobre o planejamento e o ato de ensinar nas diferentes disciplinas que integram o currículo escolar, ou sobre os procedimentos a serem assumidos nas situações cada vez mais complexas vividas no dia a dia das salas de aula das escolas brasileiras. Esta não é a direção predominante nas análises, tanto no PPG/Educação da UFRGS, quanto no Mestrado em Educação da ULBRA/ $\mathrm{RS}$, as quais têm se indagado, prioritariamente, sobre questões implicadas com representação, identidade, diferença, alteridade, poder, política cultural, pedagogias culturais, entre outras, bem como sobre os efeitos de tais questionamentos nos processos educativos examinados. Contudo, já há trabalhos ${ }^{17}$ mostrando as contribuições dos ECE para se pensar variadas esferas de ações escolares contemporâneas.

Mas cabe salientar que é nessa busca pela focalização de questões mais amplas, que parecem residir as principais contribuições que a articulação entre Educação e EC tem possibilitado, na medida em que ela impede que se proceda a uma delimitação definitiva desse campo intermediário, múltiplo ou híbrido de estudos, ou mesmo que se busque centrá-lo obrigatoriamente em uma única e definitiva direção. As análises dos ECE têm se voltado a um anteriormente negligenciado território de pesquisa, que questiona a produtividade da cultura nos processos educativos em curso nas sociedades de hoje. Então, mesmo não esquecendo que os estudos sobre Educação e os Estudos Culturais se constituíram em trajetórias históricas distintas, argumentamos que, na articulação operada entre ambos, diferenciadas temáticas, bem como múltiplas ações educativas passaram a permitir que se lide com uma gama ampliada de instituições, práticas, artefatos e produções em operação nas sociedades atuais. Foram igualmente propiciados o exame e a reflexão sobre os efeitos produtivos/ formadores/ construtivos/inventivos que tais instituições, temáticas, práticas, produções e 
artefatos têm sobre as sociedades e os sujeitos que nelas vivem.

Por outro lado, estudo desenvolvido por Costa, Silveira e Sommer (2003) aponta aproximações entre Educação e EC também em âmbito internacional. Conforme esses autores indicaram, na IV Conferência Internacional Crossroads in Cultural Studies, realizada em Tampere, Finlândia, em julho de 2002, o tópico Cultural Studies and/in/as Education (Estudos Culturais e/em/como Educação) abria um importante espaço para a dimensão educativa. Esse espaço permanece nas seguintes conferências Crossroads in Cultural Studies, realizadas até hoje, a cada dois anos, em diferentes países.

Cabe indicar, no plano nacional, que, a partir de 2004, a ULBRA passou a sediar o evento denominado Seminário Brasileiro de Estudos Culturais e Educação (SBECE), com sucessivas edições bianuais. A quinta edição, de maio de 2013, por exemplo, reuniu um importante número de participantes - mais de 600, de 21 estados brasileiros. A partir da sua quarta edição, associou-se ao SBECE o Seminário Internacional de Estudos Culturais e Educação (SIECE), uma promoção conjunta dos PPGEdu ULBRA e PPGEdu UFRGS, também com expressivo número de participações. ${ }^{18}$ Em todas as edições do SBECE e SIECE estiveram presentes tanto destacados palestrantes internacionais, como Kenneth Thompson e Daniel Mato (I SBECE) ${ }^{19}$ George Yúdice, Thomas Popkewitz, Jorge Ramos do Ó, Silvina Gvirtz, Leonor Arfuch (II SBECE), ${ }^{20}$ António Nóvoa e Mariano Narodowski (III SBECE), ${ }^{21}$ Toby Miller e Eduardo Restrepo (IV SBECE), ${ }^{22}$ Axel Rojas e Alejandro Grimson (V SBECE), ${ }^{23}$ quanto estudiosos brasileiros de campos conexos, de diferentes instituições e temáticas de estudo. ${ }^{24}$

Passamos agora a apresentar e a discutir, mesmo que brevemente, algumas das direções assumidas a partir desse encontro entre EC e Educação, circunscrevendonos, no entanto, ao que tem sido realizado em dois nichos bem definidos de produção em ECE - a linha de pesquisa Estudos Culturais em Educação do PPGEdu da UFRGS e o mestrado em Estudos Culturais em Educação do PPGEdu da ULBRA. Justificamos nossa opção por esses dois núcleos por ser neles que se verificou o movimento inicial de institucionalização dos Estudos Culturais em Educação, com a adoção oficial desta denominação. Para os objetivos do presente artigo, procedemos a um levantamento minucioso de sua produção (teses e dissertações) e, na impossibilidade de mencionar a totalidade dos trabalhos nos limites deste texto, optamos por aludir àqueles que nos pareceram melhor demonstrar aspectos de cada uma das três tendências que identificamos.

\section{Estudos Culturais e A RESSIGNIFICAÇÃO DE QUESTÕES, DISCURSOS E ARTEFATOS RELACIONADOS AO CAMPO PEDAGÓGICO}

Detemo-nos, inicialmente, nos estudos que atuam na ressignificação de questões, discursos e artefatos tradicionalmente relacionados ao campo pedagógico.

Uma revisão de dissertações e teses realizadas nos Programas de Pós-graduação em Educação da UFRGS ${ }^{25}$ e da ULBRA ${ }^{26}$ indicou que 152 desses estudos ${ }^{27}$ focalizam temas, questões, ações, práticas e programas relacionados às definições mais usuais do pedagógico. Há neles, no entanto, algumas particularidades importantes, que implicam ressignificações desse pedagógico, na medida em que tais estudos colocam ora sob suspeição, ora em discussão, ora, ainda, em associação, saberes, artefatos, conceitos e práticas educativas que foram naturalizados em função da frequência e não questionamento de sua utilização. Como indicou Stuart Hall (1997), a lógica que atua na naturalização é simples: ela implica uma estratégia representacional destinada a fixar significados, garantindo, ao mesmo tempo, um fechamento discursivo ou ideológico. Já a ressignificação, que estamos apontando ter sido um dos focos dos estudos que examinamos, se processa a partir da localização dos já referidos saberes, artefatos, conceitos e práticas pedagógicas em outros sistemas representacionais, disso decorrendo a compreensão de que essas não integram uma ordem natural. A ressignificação é, portanto, uma estratégia que se vale de um elaborado jogo que envolve o "olhar": ela implica estranhar, desfamiliarizar ou tornar explícito o que estava naturalizado, deslocando e ampliando, nesse processo, significados e seus efeitos produtivos.

Nesse sentido, identificamos, entre os estudos examinados, alguns que se ocuparam do exame da emergência de determinadas áreas de saber e de como se processou sua consolidação em programações curriculares, questionando, portanto, o estatuto de "verdade epistemológica" tantas vezes a essas atribuído. Entre esses estudos pode-se citar os desenvolvidos por Bampi (1999), Figueiredo (2001), D’Ávila (2008), Coutinho (2008) e Guimarães (2013), que focalizaram, respectivamente, os discursos que permitiram a emergência e o estabelecimento da Educação Matemática, enquanto uma área particularizada e valorizada, a organização da disciplina Prática de Estágio em uma Licenciatura em Pedagogia, na Universidade do Estado de Mato Grosso (UNEMAT), a configuração do Design como um campo diferenciado de saber, as condições de emergência da psicopedagogia no Brasil e os cenários biopolíticos em que se vem ministrando a disciplina de Sociologia no Ensino Médio brasileiro. É importante 
registrar que tais trabalhos envolveram tanto a retomada de histórias já contadas sobre esses campos de saber, quanto o enredamento de discursos de diferentes ordens, o chamamento a conceitos, o delineamento de situações ou a incursão a instâncias e circunstâncias não consideradas em estudos que os antecederam. Cabe ressaltar, ainda, que tais estudos se afastam, totalmente, das perspectivas que buscam o enquadramento epistemológico das áreas de saber examinadas.

Um segundo grupo de estudos focaliza práticas que ocorrem (embora não exclusivamente, no caso de algumas) em espaços escolares, tais como o recreio (LOPEZ, 2010), a merenda (AMARO, 2002), as brincadeiras infantis (STRAUB, 2000), o uso da internet (CASTRO, 2006), sendo importante frisar que neles não são buscadas formas mais adequadas de agir frente a possíveis "problemas" levantados. Tais estudos objetivaram indicar como tais práticas operam na constituição de identidades escolares e, também, atentar para os muitos ensinamentos desencadeados, ainda que elas não sejam entendidas como integradas ao currículo ou dotadas de uma dimensão pedagógica. Práticas de outra ordem são focalizadas na tese de Xavier (2003), que examinou como determinados instrumentos pedagógicos - fichas de secretaria, relatórios de avaliação, dossiês - atuam na constituição e disciplinamento dos alunos em uma proposta de ensino dita emancipatória, bem como na tese de Ratto (2004), que focalizou como a tradição de uso de livros de ocorrência opera em uma ótica disciplinar, que acentua traços de dependência, imaturidade e desprestígio dos estudantes, gerando a necessidade de uma constante vigilância e controle sobre eles. Já no estudo conduzido por Pinheiro (2006), a discussão centrou-se no modo como os pareceres descritivos com finalidades avaliativas estabelecem representações que instituem significados a partir de critérios de validade e legibilidade estabelecidos em tempos e espaços determinados.

Um terceiro grupo de estudos focaliza artefatos pedagógicos, tais como as cartilhas (TRINDADE, 2001), a lousa (BONACINA, 2006), as apostilas (GOMES, 2012), as gincanas e as agendas escolares (BARBOSA, 2012) e os livros didáticos de disciplinas escolares, estando, entre essas, Geografia, Inglês, Língua Portuguesa e História (OLIVEIRA, 2001; TONINI, 2002; BERGMANN, 2002; MENDES, 2007; BORBA, 2008; COSTA, 2009; BASSI, 2012). Em tais estudos, ao mesmo tempo em que se processam revisões acerca de como estes artefatos passaram a integrar a vida escolar, tais como a empreendida por Bonacina (2006) acerca da lousa, ou sobre as cartilhas, por Trindade (2001), discutemse questões particulares que dizem respeito à própria constituição dos artefatos considerados. No caso da lousa, Bonacina (2006) focalizou representações peculiares de lousa na mídia (incluindo a simbologia a ela associada) e a posicionou frente aos novos artefatos tecnológicos. No caso dos livros didáticos, foram focalizadas temáticas específicas tais como gênero (GOMES, 2006; BORBA, 2008), questões étnicas (OLIVEIRA. 2001), representações de "sem-terra" (COSTA, 2009), representações de TV (BERGMANN, 2002) colocadas em circulação nestes artefatos. Salienta-se, então, que tais análises não apenas indicam como se configuram saberes escolares nos livros didáticos, mas como neles se forjam modos de enxergar o mundo e os sujeitos que nele vivem.

Uma quarta direção de estudos focaliza propostas e programas governamentais direcionados à escola e que operam o seu governamento, estando, entre esses, os estudos conduzidos por Schineider (2009) e Lemos (2008), respectivamente, sobre o Projeto Piloto de Alfabetização do Rio Grande do Sul e o Programa Alfabetiza Rio Grande, assim como o estudo de Mello (2012) sobre a Provinha Brasil, configurada como mais um tipo de "avaliação sob medida" sobre a alfabetização e o letramento nas séries iniciais. Além desses, cabe referir o estudo conduzido por Santos (2004b) sobre as ações de governamento efetuadas nas campanhas de saúde escolar, bem como a dissertação de Muller (2008), sobre as campanhas de voluntariado na escola, e, ainda, o estudo de Krieger (2014) sobre as políticas públicas de inclusão.

Cabe salientar que muitos desses estudo ${ }^{28}$ se valeram do pensamento foucaultiano para problematizar práticas pedagógicas e políticas públicas governamentais e não governamentais relacionadas com a alfabetização, a escolarização e a docência e os modos como essas foram produzidas nas esferas social, cultural e política. Apontam para como instituições, procedimentos, reflexões, cálculos, práticas e táticas envolvidas nos processos educativos examinados implicam, gestam, deslocam, organizam e reorganizam relações de poder/saber regulando ações dos sujeitos e das populações. Neles são abordadas facetas da governamentalidade em curso nestes tempos em que, tal como salientou Gadelha (2013), coletividades e indivíduos "vêm sendo cada vez mais investidos por novas tecnologias e mecanismos de governo que fazem de sua formação e de sua educação, num sentido amplo, uma espécie de competição desenfreada cujo 'progresso' se mede pelo acúmulo de pontos, como num sistema de milhagem, traduzidos como índices de produtividade" (p. 156).

\section{ESTUdos Culturais e a ANÁlise DAS PEDAGOGIAS CULTURAIS EM OPERAÇÃO NOS DIVERSIFICADOS ESPAÇOS CONTEMPORÂNEOS}

Aproximações, análises e discussões da produção dos EC em seu encontro com a Educação evidenciam que 
um dos conceitos-chave para esta articulação tem sido o de pedagogias culturais, largamente utilizado para abordar a multiplicidade de processos educativos em curso, para além daqueles que têm lugar em instituições historicamente vinculadas a ações de educar (como é o caso da escola, da família, da igreja etc.). Em vocabulário crítico sobre teoria cultural e educação, organizado por Silva (2000, p. 89), encontramos que pode ser entendido como uma pedagogia cultural "qualquer instituição ou dispositivo cultural que, tal como a escola, esteja envolvido - em conexão com relações de poder - no processo de transmissão de atitudes e valores".

Em artigo que retoma a trajetória do conceito nas análises culturais da Educação, o norte-americano David Trend (1992) situa o entendimento que temos de pedagogias culturais como resultado de numerosos e variados embates teóricos travados nas articulações entre cultura e pedagogia. Os deslocamentos dos conceitos de cultura e de pedagogia apontam para diferentes percursos em que a primeira vai se transformando em uma dominante na qual a pedagogia assume papel central.

É nessa trajetória de debates sobre as relações entre cultura e pedagogia que os EC inauguram um espaço discursivo de grande repercussão. A "pedagogia crítica”, uma das manifestações do viés neomarxista na educação, tem em Henry Giroux (1994) um de seus expoentes, que se alinha aos EC ao conceber a pedagogia como prática cultural. Giroux (2008) e Roger Simon (2008) acoplam à pedagogia crítica também o conceito de "política cultural", e Simon, visando ampliar a noção de pedagogia, adota ainda a expressão "tecnologias culturais", referindo-se "a conjuntos de arranjos e práticas institucionais intencionais no interior dos quais várias formas de imagens, som, texto e fala são construídas e apresentadas, e com as quais, ademais, interagimos" (p. 71). Simon (id., p. 72) argumenta que tais tecnologias são desenvolvidas em espaços como "o cinema, o teatro, a televisão, a publicidade, a arquitetura, os fóruns de saúde pública, o jornalismo impresso, a música popular, os festivais onde se contam histórias e os estudos e rituais religiosos".

Hoje, em nosso país, a maior parte das pesquisas que se voltam para as pedagogias culturais embasam-se nas formulações teóricas de Giroux e McLaren (1995) e Steinberg e Kincheloe (2004). Estes últimos autores (id., p. 14) afirmam que "áreas pedagógicas" podem ser entendidas como "aqueles lugares onde o poder é organizado e difundido, incluindo-se bibliotecas, TV, cinemas, jornais, revistas, brinquedos, propagandas, videogames, livros, esportes etc." E acrescentam, mencionando Giroux, "que nosso trabalho como educadores exige que examinemos ambas, pedagogia cultural e escolar, se quisermos dar sentido ao processo educacional no final do século XX" (id., ibid.). Giroux e McLaren (1995, p. 144), por sua vez, argumentam que "existe pedagogia em qualquer lugar em que o conhecimento é produzido, em qualquer lugar em que existe a possibilidade de traduzir a experiência e construir verdades." Uma parcela considerável das pesquisas voltadas às pedagogias culturais desenvolveuse inspirada nas teorizações desses autores.

Há ainda outra peculiaridade teórica visível nos estudos que abordam as pedagogias culturais em nosso meio, a saber, as aproximações com os estudos foucaultianos e com os estudos de mídia. A contribuição dos primeiros subsidia as maneiras de pensar sobre as práticas pedagógicas como aquelas em que "se produz ou se transforma a experiência que as pessoas têm de si mesmas" (LARROSA, 1994, p. 36), sendo as relações reflexivas dos sujeitos com eles mesmos mais significativas (e efetivas!) do que as aprendizagens provenientes do "exterior". Nessa teorização, entendese que a pedagogia realiza operações constitutivas que modelam as subjetividades e fabricam sujeitos, sendo, dessa forma, educação e pedagogia, processos radicalmente históricos de transformação das pessoas. Para Larrosa (1994), é esse caráter constitutivo que faz da pedagogia uma das tecnologias mais produtivas na regulação de sujeitos, uma prática cultural dirigida à modificação dos modos de ser sujeito, um espaço de construção que atua "produzindo formas de experiência de si nas quais os indivíduos podem se tornar sujeitos de um modo particular" (p. 57). O autor argumenta que qualquer instância pedagógica que desencadeie essas ações dos sujeitos sobre eles mesmos integra dispositivos pedagógicos e "um dispositivo pedagógico será, então, qualquer lugar no qual se constitui ou se transforma a experiência de si. Qualquer lugar no qual se aprendem ou se modificam as relações que o sujeito estabelece consigo mesmo" (id., ibid.).

Os estudos de mídia, por sua vez, conectados ou não às concepções provenientes dos estudos foucaultianos, incorporam às análises das pedagogias culturais um amplo espectro de aportes acerca do papel, do significado, do poder e dos modos de operação dos artefatos midiáticos nas sociedades contemporâneas, marcadas indelevelmente pelo espetáculo, pela visibilidade, por interesses mercantis e pelo consumo. Douglas Kellner $(2001,2008)$ é um dos autores centralmente vinculado a tais discussões nos Estudos Culturais; seu livro A cultura da mídia - estudos culturais: identidade e política entre o moderno e o pósmoderno introduz o conceito de cultura da mídia - cultura que é industrial, comercial, dirigida às massas e atuante no tecido social - nos estudos sobre educação. Mediante análises de vários artefatos, o autor demonstra como essa cultura centrada na imagem joga com vasta gama 
de emoções, ideias e sentimentos, "dominando o tempo de lazer, modelando opiniões políticas e comportamentos sociais, e fornecendo o material com que as pessoas forjam suas identidades" (id., p. 9).

A proeminência das pedagogias na cena contemporânea contribuiu para um destaque crescente desse tema na agenda dos ECE, tendo sido desenvolvidas outras pesquisas com o intuito de aprofundar as discussões sobre esse foco temático. Segundo Camozzato (2012) e Camozzato e Costa (2013 e 2013a), há hoje uma proliferação e pluralização das pedagogias, expressão de um refinamento das artes de governar, regular e conduzir sujeitos. Sendo o conceito de pedagogia histórico, mutável, produzido e reproduzido nas contingências de cada tempo-espaço, é visível, na condição cultural contemporânea, que mais e mais pedagogias vão sendo inventadas para tentar dar conta do aleatório num contexto em que a educação enfrenta dificuldades. É aí que as autoras identificam o funcionamento de uma marca distintiva e produtiva das pedagogias que denominam de vontade de pedagogia. A tese de Camozzato (2012) consiste em um amplo estudo dedicado a esmiuçar as pedagogias mediante incursão por suas históricas formas e ênfases, apontando articulações com as transformações culturais e o quanto essas últimas vêm fazendo com que a pedagogia seja flexionada e pluralizada em sua denominação e espaços de atuação.

Outro estudo recente, desenvolvido por Costa e Andrade (2013), investiga especificamente os rastros do surgimento e disseminação do conceito de pedagogias culturais, assim como discute sua produtividade em estudos brasileiros que aproximam educação e comunicação, este, sem dúvida, o território investigativo privilegiado de trabalhos que fazem uso do conceito. Tal pesquisa vem ao encontro dos objetivos do presente artigo exatamente porque se debruça sobre os achados de uma amostra de estudos que têm como objeto as pedagogias culturais. São analisadas teses e dissertações para verificar como os pesquisadores operam com o conceito e o que conseguem mostrar acerca dos modos como se engendram as pedagogias que formam os sujeitos do presente. $\mathrm{O}$ corpus de análise foi composto por trabalhos ${ }^{29}$ coletados no banco de teses e dissertações da CAPES, nos quais se observou que grande variedade de artefatos culturais que circulam em espaços da mídia brasileira vem sendo analisada, destacando-se jornais, revistas, publicidade, séries de TV, desenhos animados, filmes, quadrinhos e muitos outros. Autoras e autores desses estudos operam com o conceito de pedagogias culturais para identificar, examinar e discutir as modalidades e efeitos pedagógicos de seus objetos de pesquisa.

Costa e Andrade (2013) observam distintos modos de operação das pedagogias culturais apontados nas pesquisas investigadas e aglutinam os resultados de sua análise em três tendências: a) pedagogias culturais e representação; b) pedagogias culturais e acionamento de complexos mercantis midiáticos; c) pedagogias culturais e acionamento de técnicas de cuidados de si. Sublinhamos, aqui, acompanhando as autoras, que tal categorização tem fins unicamente analíticos, e os modos de operação apontados poderiam ser mais esmiuçados, assim como outros poderiam ser identificados. Contudo, para os objetivos do presente texto consideramos adequado expor sucintamente cada uma das tendências apontadas no trabalho de Costa e Andrade (id.).

Pedagogias culturais e representação - Nessa tendência de estudos, o conceito de representação é tomado como central para mostrar que, ao representar modos de ser sujeito mediante atribuição de um conjunto de significados, os artefatos da mídia "criam padrões, modelos desejáveis, que educam e produzem sujeitos constituídos segundo seus preceitos" (id., p. 9). Segundo as teses e dissertações que adotam o conceito de representação, aprende-se a ser sujeito de certo tipo em imagens, discursos e narrativas que circulam em filmes, revistas, jornais etc.; as pedagogias culturais operariam produzindo e fazendo circular tais representações que funcionam como modelos, inspiram e convocam os sujeitos. Silva (2010b), por exemplo, ao estudar o artefato cinema, defende que "a função pedagógica do cinema está sempre presente", já que, ao assistirem a filmes, os sujeitos "também aprendem valores e modos de ser a partir das representações veiculadas" (p. 19). Costa e Andrade (2013) sublinham que esses trabalhos onde a representação é apontada como central no modo de operação das pedagogias culturais estão, em maior ou menor grau, afinados com os estudos de Kellner (2001) sobre a cultura da mídia, cujo argumento é que "o rádio, a televisão, o cinema e os outros produtos da indústria cultural fornecem os modelos daquilo que significa ser homem ou mulher, bem-sucedido ou fracassado, poderoso ou impotente" (p. 9).

Pedagogias culturais e acionamento de complexos mercantis midiáticos - Esse modo de operação das pedagogias culturais ressalta os vínculos entre mídia e consumo, e os pesquisadores procuram mostrar estratégias com as quais múltiplos artefatos culturais são acionados para mobilizar crianças e jovens em direção ao consumo. Nos estudos analisados, observa-se que, mediante a composição de um "complexo mercantil midiático (brinquedos, filmes, CDs, vestuário, livretos, quadrinhos, adornos etc.)", é criado um conjunto sempre ampliado e renovado de imagens, propostas e ofertas atraentes, que, de diferentes maneiras, constantemente convocam os sujeitos ao consumo. Dentre outros trabalhos, Flor (2007) e Prates (2008) construíram seus objetos de pesquisa 
entendendo-os como "complexos", com o objetivo de tornar visível certo modo de formar consumidores em que se aglutina um conjunto de artefatos em torno de um acontecimento midiático gerador ou nuclear. A pesquisa de Flor (2007) analisa o "Complexo Rebelde" (novela, banda musical, álbuns, roupas, shows de TV e ao vivo etc.) e Prates (2008) toma como objeto de estudo o "Complexo W.I.T.C.H." (desenho animado, revistas, manuais, talismãs, poções e adereços). Ambos objetivam mostrar as minuciosas e sofisticadas táticas que atraem, capturam e dirigem condutas de crianças e jovens atrelados a suas redes de consumo, mesmo que isso ocorra em um recorte temporal determinado e efêmero. Carvalho (2002) analisa o McDonald's e utiliza o entendimento teórico de imagens pós-fotográficas ${ }^{30}$ que, intercambiando significados com as pessoas, estariam implicadas na criação da "cultura do McDonald's", repleta de artefatos como caixas de lanche, joguinhos, guardanapos etc. Segundo esse pesquisador, sujeitos contemporâneos interagem com essa cultura e se educam de acordo com os objetivos daquela empresa. Segundo Carvalho (id.), a sociedade do espetáculo produz sua própria pedagogia e os artefatos da rede McDonald's operam como lições pedagógicas "através de imagens, que trazem à nossa cultura conceitos, valores, ensinamentos e versões sobre múltiplos aspectos de nossa vida sociocultural." (p. 42).

Segundo Costa e Andrade (2013), nessa tendência de estudo das pedagogias culturais observa-se que é mediante a composição desses complexos, com seu universo imagético e comercial, que entram em operação as pedagogias culturais. Os pesquisadores nos mostram que inserir os sujeitos contemporâneos nesse "universo de imagens, espetáculo e convocações irrecusáveis" é uma forma de fazer com que "aprendam sobre si, sobre os outros, sobre o mundo e sobre tudo aquilo que tais complexos consideram desejável para que seus conglomerados mantenham-se lucrativos e alinhados ao capitalismo neoliberal contemporâneo." (id., p. 11).

Pedagogias culturais e cuidados de si - Aqui inscrevem-se as pesquisas inspiradas nos estudos foucaultianos em conexão com estudos de mídia, sendo que as práticas consideradas evidências das pedagogias culturais aludem aos cuidados/técnicas de si, ao governo das condutas, à produção de subjetividades. Além dos autores já mencionados como referencial nos trabalhos sobre tais pedagogias, as pesquisas de Rosa Maria Fischer $(1996,1997)$ têm sido inspiradoras, na medida em que a autora entende que compete à mídia formar seu público, seus próprios leitores/telespectadores.

$\mathrm{Na}$ linha dessa perspectiva de estudos, a tese de Thoma (2002) apresenta o cinema como um dos dispositivos contemporâneos que molda identidades, sendo que "a pedagogia cultural do cinema ocorre, então, através das lições sobre como devemos ser, agir, pensar e nos comportar frente a nós mesmos e aos outros" (p. 97). Outra pesquisa, a de Ferrari (2009), analisa a revista Você $S / A$ e aponta que nesse artefato uma pedagogia cultural opera "a partir do momento em que, corporificando uma cultura de negócios, criando ferramentas e estratégias de gestão, descreve e prescreve comportamentos, atitudes e dimensões da própria aparência pessoal para os candidatos a empregos" (p. 26). No já mencionado estudo de Prates (2008), ao analisar o "Complexo W.I.T.C.H.", a pesquisadora vai demonstrando "os modos como tal complexo opera para que as jovens meninas, fascinadas consumidoras dos artefatos do complexo, atuem sobre si mesmas a partir dos ensinamentos por eles veiculados." (p. 144). A autora ressalta que, "ao esmiuçar as táticas dessa pedagogia cultural", observou-se "um certo tipo de tecnologia do eu funcionando, e também algumas dimensões de um processo de subjetivação que vai formando consumidores" (PRATES, 2008, p. 145). Ao longo de seu estudo, tecnologias do eu e processos de subjetivação foram os tópicos desenvolvidos para demonstrar a produtividade da mídia e das pedagogias culturais na formação de sujeitos jovens. A própria autora refere que vê "o complexo W.I.T.C.H. como certa modalidade de aparato pedagógico" implicado num processo de construção de um sujeito de certo tipo. Neste sentido, o considera como uma pedagogia cultural, entendendo que ele "opera sobre a vida das garotas, mediando esse processo de constituição e de composição de subjetividades e identidades em que estão implicadas experiências de si” (id., ibid.).

Investigar os contornos e ênfases das pedagogias tornase então crucial quando as teorias sociais e culturais se ocupam centralmente com a formação das subjetividades engendradas pelos modos de vida contemporâneos que modelam corpos e mentes. Camozzato e Costa (2013) afirmam que as pedagogias se multiplicaram e diversificaram no deslocamento da sociedade do ensino para a da aprendizagem, tal como apontam autores como Fauré (1977) e Noguera-Ramírez (2009), e as pesquisas em educação desenvolvidas na perspectiva dos EC da vertente pós-estruturalista têm mostrado essa pluralidade de pedagogias em atividade nos múltiplos espaços e artefatos que circundam, transcendem e atravessam a escola. Nessa movimentação, de acordo com Camozzato e Costa (id., p. 23), a pedagogia tem "atuado como uma operadora dos discursos que intentam nos constituir", é dotada de plasticidade e corresponde a uma "contínua vontade de investir e atuar sobre todos os aspectos e âmbitos da vida dos sujeitos contemporâneos - o que faz de cada um de nós um agente de incessante transformação e atuação com os saberes." (id., ibid., p. 23). 


\section{ESTUdOS CULTURAIS E ABORDAGENS DE IDENTIDADE E DIFERENÇA NO CAMPO DA EDUCAÇÃO NO BRASIL}

Para apresentarmos brevemente as principais contribuições que a articulação entre os EC e a Educação no Brasil trouxe para a abordagem da diferença-identidade, relembremos de início o quanto seus sistemas educativos e instituições escolares, assim como a legislação e os materiais pedagógicos, por muitas décadas privilegiaram um determinado modelo de sociedade ideal (ocidental, europeizada, "civilizada") e uma representação de mundo e de sujeito com uma (1) norma - branca, heterossexual, letrada, cristã, ouvinte, para apenas citar alguns dos atributos correntes. A despeito da existência de uma sociedade miscigenada e híbrida, integrada por inúmeros e distintos grupos culturais, com tradições, práticas, concepções e modos de vida diversos, a escola brasileira, sob a inspiração de ideais ditos universalistas (que nada mais eram do que a atribuição de "universal" a alguns parâmetros e atributos, com a desqualificação dos outros), pouco se abria à diferença, mesmo quando os "diferentes" começaram a acorrer a ela. No caso de acolhê-los, o fazia sob o manto do exótico e/ou do deficitário (que inspirava curiosidade e/ou merecia compaixão, condescendência, benevolência ou correção de comportamentos, em outros casos).

Foi apenas há poucas décadas que começaram a se esboçar tendências de mudanças nesse estado de coisas. Os movimentos feministas, em primeiro lugar, os movimentos negros, as lutas dos indígenas, os movimentos LGBT e o movimento surdo, entre vários outros, contribuíram para abalar esta imagem unificada de sujeito desejável e universal, ao mesmo tempo que, conforme já mencionamos, na década de 1990 começam a ser lidos no Brasil textos do campo dos Estudos Culturais, notadamente de Stuart Hall, Lawrence Grossberg, Kathrin Woodward, entre outros, os quais vieram contribuir para o posicionamento, no campo acadêmico da Educação, da questão das diferenças e identidades. Ao afirmar que "a visão de identidade dominantemente aceita no âmbito dos Estudos Culturais apresenta inestimáveis contribuições para o tratamento das identidades no currículo e na prática pedagógica”, Moreira (2011, p. 129) observa que esses "outros", que tradicionalmente escapavam aos contornos do desejável e do correto no campo educativo e social mais amplo, "têm buscado garantir e ampliar seu espaço, afirmando sua identidade como outra possibilidade de construção do humano" (id., ibid.). Sem dúvida, a abordagem das identidades e diferenças, fartamente explorada pelos ECE no Brasil, articulados com outros campos de estudos limítrofes, tem repercutido em muitos âmbitos do pedagógico, entendido tanto em seu sentido estrito, quanto no mais amplo, como vimos nas seções anteriores.

A partir desse fundamento, é possível rastrear, no campo acadêmico brasileiro, estudos da última década, inspirados nos ECE, que têm questionado o tradicional apagamento das diferenças no âmbito pedagógico e perscrutam analiticamente algumas dimensões da diferença - a etnia (em especial negros e indígenas); o gênero e a orientação sexual; a deficiência, em cujo âmbito tem se destacado a questão da surdez, com o florescimento dos Estudos Surdos; a idade e a conformação corporal, entre outras. Entre as várias possibilidades de rastreamento dos aportes que os estudos brasileiros no campo dos ECE têm trazido ao debate, optamos pela localização de algumas teses e dissertações defendidas nos últimos dez anos, assim como de uma obra, as quais focalizam algumas dessas diferenças, apenas a título de exemplificação.

Assim, é possível constatar que a conexão entre reflexões trazidas pelos $\mathrm{EC}$ e as abordagens das questões de gênero tem se revelado bastante frutífera no primeiro campo. Uma dissertação como a de Vargas (2008), intitulada Meninas (mal) comportadas: posturas e estranhamentos em uma escola pública de periferia, exemplifica a utilização de uma metodologia de inspiração etnográfica para adentrar uma escola de periferia, buscando, como afirma a autora, "visibilizar e problematizar posturas e posicionamentos de alunas [...] considerados distantes das representações clássicas de infância feminina" (p. 120). Ao identificar essas meninas, frequentemente narradas como "briguentas, assanhadas, atiradas" (p. 121) por outros atores do ambiente escolar, a autora mostra com viveza as quebras e fissuras das representações circulantes sobre o gênero feminino. Através do registro de formas com que as meninas se constituíam no cotidiano escolar, Juliana arrola expressões orais e escritas corriqueiras no grupo de convivência, comportamentos típicos dos momentos de entrada e saída da escola, de sala de aula e recreio; situações de violência física e verbal em que algumas conquistavam posições de maior valorização frente ao grupo; posturas em relação a relacionamentos amorosos, traços estes que Juliana englobou genericamente sob a expressão de "protagonismo feminino". Tais aspectos, identificados como as principais marcas da identidade dessas meninas "malcomportadas", levaram a autora, na conclusão de seu trabalho, a se perguntar sobre como seu estudo poderia contribuir para o cotidiano da escola frequentada por essas meninas e por outros grupos que partilham marcas de tal identidade. Como possível resposta, Juliana aponta que entender melhor estas identidades de meninas, em ambientes específicos, pode ser um caminho para que "as escolas possam encontrar 
formas próprias para trabalhar com as suas meninas na contemporaneidade" (p. 124).

Já entre aqueles estudos que se debruçam sobre pedagogias culturais (e artefatos escolares, também), vários deles, como apontado na seção anterior, percorreram os meandros da TV, as ilustrações e os textos dos livros didáticos, as variadas revistas, os desenhos animados, compondo um quadro de asserções, imagens, conselhos que descrevem e prescrevem formas de ser mulher (e homem) na contemporaneidade. Ilustrando a abordagem dessa temática através das pedagogias culturais, está o trabalho $A$ invenção da infância generificada: a pedagogia da mídia impressa constituindo as identidades de gênero, de Santos (2004), que tomou como material de análise revistas brasileiras sobre a temática "infância", como Crescer, Pais \& Filhos e Meu Nenê e Família, para examinar como tais artefatos operam discursivamente - através dos textos e imagens - na constituição das identidades de gênero na infância. Perscrutando matérias sobre decoração de quartos de bebês e de crianças, sobre os brinquedos, sobre moda para meninos e meninas e, também, sobre educação, saúde e alimentação, Cláudia observou como "comportamentos e disposições masculinos e femininos são apresentados de forma binária e dicotômica, lançando-se mão de justificativas advindas dos discursos das áreas psi e bio".

Outro campo que tem apresentado um grande incremento e uma produção acadêmica com visíveis efeitos sobre lutas educacionais é o que diz respeito à cultura surda e à identidade surda, em trabalhos que se inspiraram nos EC e nos chamados Estudos Surdos e se espalharam por várias universidades brasileiras. Tais estudos buscam, por exemplo, analisar as representações de surdo e surdez vigentes em diversos textos - desde os midiáticos até os legais - e conectar tais análises com lutas políticas de reconhecimento da surdez como criadora de uma cultura e não como uma marca de deficiência, frente ao mundo ouvinte normalizador. Rejeitando uma visão clínica da surdez, vários desses trabalhos estão estreitamente vinculados a ações e posturas políticas dos grupos surdos, em defesa do direito ao seu reconhecimento cultural. Se esta foi a tendência dominante nos primeiros trabalhos ligados ao tema, avultam nos últimos anos os estudos que se debruçam sobre um espectro mais aberto da Cultura Surda. Exemplos desta produção podem ser encontrados nos trabalhos enfeixados na obra Cultura surda na contemporaneidade - negociações, intercorrências e provocações, organizada por Karnopp, Klein e LunardiLazzarin (2011), três autoras com formação e atuação no campo dos EC, obra que é caracterizada explicitamente como filiada aos EC, "por entender a cultura como campo de luta em torno de significação social", e aos Estudos Surdos, "por conceber a cultura surda como espaço de contestação e de constituição de identidades e diferenças que determinam a vida de indivíduos e de populações" (p. 16). Enfatizando a ideia de que a cultura surda não se localiza de forma fechada e autolimitada, as autoras acentuam seu caráter híbrido e flutuante, abrindo espaço, na obra, a vários estudos em que se articulam questões de identidade surda e também de pedagogias culturais que circulam em diversos espaços. Um site como o YouTube, por exemplo, serve de campo para análise de vídeos em que representações-identidades de surdos são discutidas (PINHEIRO, 2011, p. 36); outros trabalhos se debruçam sobre a literatura surda, ora sobre as narrativas de si, ora sobre produções em vídeo em Língua de Sinais (recordemos que a Língua Portuguesa, como qualquer língua de base oral, é uma segunda língua para surdos), ora em outras dimensões ainda.

Também a abordagem da velhice, da identidade do velho e da velha - este "outro" incômodo - vista como construção cultural de uma idade de corpo, tem sido produtiva nos estudos acadêmicos inspirados nos EC. Assim encontramos trabalhos que desvendam formas de representação e significados sobre a velhice, tanto em artefatos ligados ao marketing, como em redes sociais da internet, em filmes, em sites, os quais têm mostrado a coexistência de representações que emergiram nas últimas décadas - como a dos velhos que devem se manter ativos e são responsabilizados pela própria saúde e bem-estar - e de representações de velhice com larga tradição, como a dos velhos doentes, mal humorados, incapazes, que devem ficar em casa e se restringir às atividades dos tempos pregressos, pois perturbam os ambientes que frequentam. $\mathrm{Na}$ dissertação intitulada Velha é a vovozinha: estratégias de marketing ensinando às mulheres "novas" formas de envelhecer, Cardoso (2007) analisa ações de marketing que têm contribuído para produzir determinados significados e identidades desejáveis para mulheres velhas, tomando como seu objeto central de análise a produção de um calendário organizado por uma empresa gaúcha, sob a inspiração do filme britânico Calendar Girls, para o qual posaram mulheres do grupo etário referido. Em tal análise, o autor promove a desnaturalização de representações dos sujeitos dessa "idade da vida", mostrando como o marketing produz efeitos sobre os seus corpos, desejos, hábitos, crenças, valores e subjetividades.

Já Brandão (2009), em sua dissertação de Mestrado, analisa representações da velhice nos discursos juvenis de comunidades do Orkut, então um site de relacionamentos de grande penetração no Brasil, que, à época, ainda não estava sujeito a controles sobre eventuais conteúdos preconceituosos. A autora se debruçou sobre comunidades escolhidas por tematizarem a questão dos velhos e terem uma quantidade significativa de membros, 
identificando tanto aquelas que expressavam desprezo e ódio pelos velhos, ridicularizando-os e zombando deles, quanto outras que louvavam sua experiência e sabedoria, sendo estas frequentemente conectadas à figura dos avós. Nas primeiras, encontravam-se menções à sua lentidão, à sua presença indesejada em lugares públicos, à aversão aos velhos "assanhados", aos velhos no volante, aos que estavam nas redes sociais e, ainda, à linguagem usada por eles, menções estas pontuadas por palavras ofensivas e expressões de escárnio. Já nas comunidades que sinalizavam respeito e admiração, encontravam-se palavras carinhosas e demonstração de afeto e de gratidão pelos ensinamentos. Esta coexistência de representações também se mostrou imbricada com as pedagogias culturais exercidas pelo espaço virtual, num intercâmbio já mencionado na seção anterior sobre as referidas pedagogias. Já Strassburger (2011), utilizando entrevistas e observações, voltou-se para um conhecido grupo de teatro de mulheres de terceira idade de Porto Alegre, o "Sem Teias", investigando as pedagogias culturais postas em ação pelo grupo, em suas apresentações e discussões com a plateia. O trabalho evidenciou que a representação dominante de velhice que circulava no grupo de teatro e que era posta a operar em seu trabalho era de uma velhice ativa, o que emergia não apenas da encenação teatral, como também do fato de as atrizes serem consideradas exemplos de uma velhice bem-sucedida.

Também na esteira da abordagem das identidades e diferenças sob a inspiração dos EC, vale a pena mencionar a existência de vários trabalhos sobre juventude, suas práticas (de lazer, de escuta, de produção cultural), especialmente aquelas que objetivam marcar uma identidade própria dentro e fora do espaço escolar. É possível, neste sentido, localizar estudos que se reportam à juventude como uma construção cultural de uma "idade do corpo", entendimento que tem sido usual nos trabalhos acadêmicos inspirados nos EC, e que exploram formas de representação e significados de juventude em artefatos publicitários, redes sociais, sites da internet, filmes e, também, em narrativas e práticas juvenis que constroem suas identidades em espaços urbanos vistos também como espaços pedagógicos. ${ }^{31}$ Nesta vertente, localizam-se, por exemplo, os trabalhos de Quadros (2011) e de Silva (2010a), que lançaram mão de estratégias de investigação da etnografia pós-moderna. Em sua tese, a primeira autora buscou mostrar e compreender a produtividade das práticas de escuta de artefatos sonoros portáteis por jovens urbanos contemporâneos, para a construção de identidades e culturas juvenis. Vendo tais ações como práticas com múltiplas significações, portanto, práticas culturais, a autora logrou mostrar a eficiência das mesmas na constituição de determinadas identidades juvenis e de um estilo de vida que tem a conectividade como característica mais forte.

Já o estudo de Silva (2010a) problematizou práticas culturais de tribos de jovens grafiteiros e pichadores em espaços urbanos de Porto Alegre, lançando mão, como recursos metodológicos, de fotografias, filmagens, diários de campo, entrevistas e conversas que possibilitaram a construção de um original conjunto de dados para sua investigação. Nas conclusões de sua pesquisa, ele assinala que, ao demarcarem territórios urbanos, os grafiteiros e pichadores promovem outros mapeamentos urbanos em que o corpo orgânico dos jovens sujeitos e o corpo de concreto da cidade se fundem numa espécie de pele urbana. Além disso, o autor observa que, se, por um lado, os graffiti e as pichações produzem outras pedagogias que se situam fora dos espaços formais de educação, por outro, observa-se que sua utilização em espaços institucionais (como escolas, museus e galerias de arte) vem acarretando uma pedagogização das mesmas. Por fim, Silva registra que a característica transgressora de tais práticas culturais também permitiu a ele, como pesquisador, uma aproximação às formas plurais de resistências que são manifestadas nos cotidianos juvenis urbanos.

Esta breve abordagem não esgotou todas as "diferenças" e "identidades" que têm sido estudadas no campo dos ECE no Brasil, não se demorando, por exemplo, nos estudos sobre identidades indígenas, regionais (gaúchas), negras, relacionadas às formas do corpo etc. De qualquer forma, pensamos ter sido possível esboçar um quadro de como a inspiração dos EC tem potencializado estudos brasileiros que articulam a questão das identidades e a área da educação. Tais estudos mostram que os discursos que circulam nos artefatos especificamente pedagógicos (livros e materiais didáticos em geral) e também nos que englobam pedagogias culturais mais amplas (revistas, filmes, desenhos animados, programas de TV), como vimos anteriormente, não são fixos nem uniformes. Ao incorporarem atitudes de benevolência, tolerância, normalização e/ou fixação de características, alguns discursos atuam na reafirmação de atributos aceitos e mais valorizados de uma única identidade, considerada desejável; outros, entretanto, orientam-se para uma busca de quebra de estereótipos e de afirmação de novas identidades, que também buscam espaços para se autorrepresentarem e terem seus direitos reconhecidos e atendidos.

\section{Palavras finais}

Parece uma tarefa quase impossível retomar e discutir o que se pode nomear como uma pequena história da articulação dos Estudos Culturais e Educação no 
panorama acadêmico brasileiro, nos necessários limites de um artigo. Sobrevoos, simplificações e inevitáveis omissões acabam acontecendo, num movimento que de certa forma - potencializa, para o leitor e a leitora, a relevância das Referências (bibliográficas) que o seguem, onde podem ser buscadas informações mais precisas, discussões mais completas, apropriações mais nítidas. Nos parágrafos finais do texto, portanto, limitamo-nos apenas a apontar alguns aspectos cuja relevância queremos frisar.

Assim é que uma dimensão que se pretende enfatizar diz respeito à afirmação de que os ECE ampliaram o que se entendia como educativo e pedagógico! Como vimos a partir dos vários estudos citados (e, podemos dizer, de muitos outros), essa ampliação implica não apenas ressignificações de entendimentos sobre a escola e o que nela sucede - a mercantilização embutida nas práticas escolares, nos currículos, nos vestuários de escolares, por exemplo -, mas também a ideia de que os artefatos culturais operam como pedagogias potentes, o que indica, tal como enfatizou Barbero (2014), estarmos passando de "uma sociedade com sistema educativo para uma sociedade educativa [...] cuja rede educativa atravessa tudo: o trabalho e o ócio, o escritório e o lar, a saúde e a velhice" (p. 10). Muitos dos estudos referidos - tanto as análises textuais e discursivas, mesmo as de inspiração foucaultiana, quanto os estudos de campo apoiados nas etnografias ou variações desses - ocupam-se com esta multiplicação do pedagógico, registrando ora como se tem procedido a deslocamentos, ora como se têm colocado em destaque novos personagens no cenário escolar contemporâneo - as lolitas, os funkeiros, as meninas malcomportadas -, não deixando de atentar para aqueles outrora confinados a instituições especializadas (ou a suas casas) - os cegos, os surdos, os "deficientes", os necessariamente posicionados "nas margens" em função de atributos de gênero, etnia, orientação sexual, idade etc. Ampliaram-se, assim, também, as categorias de sujeitos que povoam os processos educativos, buscando-se escapar do que Barbero (ibid.) refere ser a unicidade do olhar. Argumentamos, portanto, que estamos fazendo, nos ECE, investigações eminentemente voltadas a processos educativos. Trata-se, porém, de um educativo múltiplo e ampliado, a partir, especialmente, das reconfigurações dos modos como o saber circula nas sociedades contemporâneas - disperso, fragmentado, escapando dos lugares sagrados que anteriormente o continham e legitimavam, bem como das figuras sociais que o detinham e administravam, tal como igualmente salientou Barbero (ibid.).

Salientamos, ainda, que o esquadrinhamento desse educativo nos coloca desafios metodológicos importantes que implicam, por exemplo, a realização de estudos cada vez mais híbridos, que muitas vezes articulam pesquisas de campo com análises de textos variados (desde os legais até os produzidos em situação de entrevistas e conversas, por exemplo), análises de imagens, documentações fotográficas, investigações na internet etc. Não pretendemos, por certo, idealizar as possibilidades compreensivas que os ECE podem oferecer em relação às problemáticas educativas dos dias atuais, mas intentamos mostrar a inserção do campo no leque de perspectivas que se preocupam com análises do pedagógico.

De certa forma, pensamos que a articulação entre os Estudos Culturais e a Educação no Brasil corresponde a um dos traços que um dos seus "pais fundadores", Stuart Hall, identificou nos primeiros, em entrevista concedida a Miguel Mellino (HALL; MELLINO, 2011, p. 25): “[...] los Cultural Studies surgieron contaminándose com otros campos y contaminándolos a su vez. Desde siempre se proponen como campo híbrido y transdisciplinario, contingente, en constante formación [...]" E, para além da metáfora da contaminação, que nos parece produtiva para pensarmos a articulação entre EC e educação, talvez possamos tomar como ponto de reflexão as palavras de Hall, ao desenvolver sua resposta a Mellino:

\begin{abstract}
Todos necesitamos traducir constantemente ideas y conceptos en situaciones específicas: esta continua necesidad de traducción es, de nuevo, lo que he denominado 'teorizar'. [...] Concibo la teoria como processo: mi 'go on theorizing' implica redefinir constantemente nuestros conceptos, dejar de pensar de cierto modo y empezar a pensar de otro, más adecuado a nuestro própio contexto. Sin este proceso de traducción y esclarecimiento es imposible desarrollar Cultural Studies en situaciones siempre distintas (id., p. 30-31).
\end{abstract}

\section{REFERÊNCIAS}

AMARO, Lúcia Elena Matos. Tem repetição professora?...: um estudo sobre a prática da merenda escolar e seus significados. 2002. 89 f. Dissertação (Mestrado em Educação) - Faculdade de Educação, Universidade Federal do Rio Grande do Sul, Porto Alegre, 2002.

BAMPI, Lisete Regina. O discurso da educação matemática: um sonho da razão. 1998. Dissertação (Mestrado em Educação) - Faculdade de Educação, Universidade Federal do Rio Grande do Sul, Porto Alegre, 1998.

BARBERO, Jesús Martín. A comunicação na educação. São Paulo: Contexto, 2014.

BARBOSA, Mirtes Lia Pereira. Cuide da saúde: aprendendo a ser saudável em gincanas e agendas escolares. 2012. $240 \mathrm{f}$. Tese (Doutorado em Educação) - Faculdade de Educação, Universidade Federal do Rio Grande do Sul, Porto Alegre, 2012.

BASSI, Marcos Ivan. O livro didático de História: uma análise a partir de representações de regionalidade. 2012. 206 f. Dissertação (Mestrado em Educação) - Faculdade de Educação, Universidade Luterana do Brasil, Canoas, 2012. 
BERGMANN, Leila Mury. Representações da TV no livro didático de língua portuguesa. 2002. Tese (Doutorado em Educação) - Faculdade de Educação, Universidade Federal do Rio Grande do Sul, Porto Alegre, 2002.

BONACINA, Vera Lúcia. Representações da lousa na mídia escrita: um estudo em revistas semanais. 2006. $162 \mathrm{f}$. Dissertação (Mestrado em Educação) - Faculdade de Educação, Universidade Luterana do Brasil, Canoas, 2006.

BORBA. Rosa Maria Zilles. Representações da figura feminina em livros didáticos de inglês dos anos sessenta. 2008. 100 f. Dissertação (Mestrado em Educação) - Faculdade de Educação, Universidade Luterana do Brasil, Canoas, 2008.

BRANDÃO, Maria de Fátima M. Representação da velhice nos discursos juvenis em comunidades do Orkut. 2009. 115 f. Dissertação (Mestrado em Educação) - Faculdade de Educação, Universidade Luterana do Brasil, Canoas, 2009.

CAMOZZATO, Viviane Castro. Da pedagogia às pedagogias: formas, ênfases, transformações. 2012. 203 f. Tese (Doutorado em Educação) - Faculdade de Educação, Universidade Federal do Rio Grande do Sul, Porto Alegre, 2012.

CAMOZZATO, Viviane Castro; COSTA, Marisa Vorraber. Vontade de pedagogia - pluralização das pedagogias e condução de sujeitos. Cadernos de Educação da UFPel, n. 44, jan./abr. 2013. Disponível em: <http://periodicos.ufpel.edu.br/ojs2/ index.php/caduc/article/viewFile/2737/2489>. Acesso em: 20 abr. 2014

CAMOZZATO, Viviane Castro; COSTA, Marisa Vorraber. Da pedagogia como arte às artes da pedagogia. Pro-posições, Campinas, v. 24, n. 3, set./dez. 2013a.

CARDOSO, Áureo Vandré. Velha é a vovozinha: estratégias de marketing ensinando às mulheres "novas" formas de envelhecer. 2007. 143 f. Dissertação (Mestrado em Educação) - Faculdade de Educação, Universidade Luterana do Brasil, Canoas, 2007.

CARVAlHO, Alexandre Filordi de. Além dos arcos dourados: a pedagogia cultural do Mcdonald's. 2002. $130 \mathrm{f}$. Dissertação (Mestrado em Educação) - Faculdade de Educação, Universidade Estadual de Campinas, Campinas, 2002.

CASTRO, Fernanda Santos de. Navegadores na escola: identidade cultural em tempos de internetês. 2006. $103 \mathrm{f}$. Dissertação (Mestrado em Educação) - Faculdade de Educação, Universidade Luterana do Brasil, Canoas, 2006.

COSTA, Andresa Silva da. O dispositivo de racionalização da pobreza nas pedagogias contemporâneas: um estudo sobre as representações dos sem-terra no livro didático de história. 2009. 129 f. Dissertação (Mestrado em Educação) - Faculdade de Educação, Universidade Luterana do Brasil, Canoas, 2009.

COSTA, Marisa Vorraber. Poder, discurso e política cultural: contribuições dos Estudos Culturais ao campo do currículo. In: LOPES, Alice Casemiro; MACEDO, Elizabeth (Org.). Currículo: debates contemporâneos. São Paulo: Cortez, 2002.

COSTA, Marisa Vorraber. Sobre as contribuições das análises culturais para a formação de professores no início do século XXI. Educar em Revista, n. 37, p. 129-152, maio/ago. 2010.

COSTA, Marisa Vorraber; ANDRADE, Paula Deporte. Na produtiva confluência entre educação e comunicação, as pedagogias culturais contemporâneas. In: $36^{\mathrm{a}} \mathrm{RN}$ ANPED, Goiânia, out. 2013. GT 16 "Educação e Comunicação".
Disponível em: <http://36reuniao.anped.org.br/pdfs_trabalhos aprovados/gt16_trabalhos_pdfs/gt16_2912_texto.pdf $>$. Acesso em: 14 abr. 2014 .

COSTA, Marisa Vorraber; SILVEIRA, Rosa Hessel; SOMMER, Luis Henrique. Estudos culturais, educação e pedagogia. Revista Brasileira de Educação, n. especial - Cultura, culturas e educação. n. 23, p. 36-61, maio/ago. 2003.

COUTINHO, Karyne Dias. A emergência da psicopedagogia no Brasil. 2008.219 f. Tese (Doutorado em Educação) Faculdade de Educação, Universidade Federal do Rio Grande do Sul, Porto Alegre, 2008.

D’ÁVILA, Cid Domingues. Desenhando o design: um olhar sobre discursos que instituem - e ensinam - o que é design e o que é ser designer. 2008. 126 f. Dissertação (Mestrado em Educação) - Faculdade de Educação, Universidade Luterana do Brasil, Canoas, 2008.

FAURÉ, Edgar. Aprender a ser. 2. ed. Lisboa: Bertrand, 1977. FERGUSON, Marjorie; GOLDING, Peter. Cultural Studies and changing times: an introduction. In: FERGUSON, Marjorie; GOLDING, Peter (Ed.). Cultural Studies in question. London/ ThousandOaks/New Delhi: Sage, 1997.

FERRARI, Fernanda da Luz. Você S.A. - Um estudo da produção de "profissionais adequados" nas matérias sobre seleção de pessoal. 2009. 128 f. Dissertação (Mestrado em Educação) - Faculdade de Educação, Universidade Luterana do Brasil, Canoas, 2009.

FIGUEIREDO, Jocinete das Graças. A prática de ensino e o estágio supervisionado no curso de Pedagogia da Universidade do Estado do Mato Grosso: uma análise a partir dos estudos culturais. 2001. Dissertação (Mestrado em Educação) - Faculdade de Educação, Universidade Federal do Rio Grande do Sul, Porto Alegre, 2001.

FISCHER, Rosa Maria Bueno. O estatuto pedagógico da mídia: questões de análise. Educação \& Realidade, v. 22, n. 22, p. 59-80, jul./dez. 1997.

FISCHER, Rosa Maria Bueno. Adolescência em discurso: mídia e produção de subjetividade. 1996. Tese (Doutorado em Educação) - Faculdade de Educação, Universidade Federal do Rio Grande do Sul, Porto Alegre, 1996.

FLOR, Douglas. A convocação para o consumo nas pedagogias culturais: circuitos e teias do complexo rebelde. 2007. 140 f. Dissertação (Mestrado em Educação) - Faculdade de Educação, Universidade Luterana do Brasil, Canoas, 2007.

GADELHA, Sylvio. Biopolítica, governamentalidade e educação: introdução e conexões a partir de Michel Foucault. 1. reimpr. Belo Horizonte: Autêntica, 2013.

GIROUX, Henry. Doing cultural studies: youth and the challenge of pedagogy. Harvard Educational Review, v. 64, n. 3, p. 278-308, Fall 1994. Disponível em: <http://www. henryagiroux.com/online_articles/doing_cultural.htm $>$. Acesso em: 28 abr. 2014.

GIROUX, Henry. Memória e pedagogia no maravilhoso mundo da Disney. In: SILVA, Tomas da (Org.). Alienígenas na sala de aula: uma introdução aos Estudos Culturais em educação. 7. ed. Petrópolis: Vozes, 2008.

GIROUX, Henry; MCLAREN, Peter. Por uma pedagogia crítica da representação. In: SILVA, Tomaz Tadeu; MOREIRA, 
Antônio Flávio (Org.). Territórios contestados: o currículo e os novos mapas culturais. Petrópolis: Vozes, 1995.

GOMES, João Carlos A. As representações de gênero nas imagens dos livros didáticos de Ensino Médio. 2006. 158 f. Dissertação (Mestrado em Educação) - Faculdade de Educação, Universidade Luterana do Brasil, Canoas, 2006.

GOMES, João Carlos A. As apostilas dos sistemas de ensino sob uma lógica empresarial. 2012. $221 \mathrm{f}$. Tese (Doutorado em Educação) - Faculdade de Educação, Universidade Federal do Rio Grande do Sul, Porto Alegre, 2012.

GROSSBERG, Lawrence. Existe lugar para os intelectuais no novo radicalismo? Três paradigmas. In: SARAIVA, Karla; MARCELLO, Fabiana de Amorim (Org.). Estudos Culturais e educação: desafios atuais. Canoas: Editora da ULBRA, 2012.

GROSSBERG, Lawrence. Será que os Estudos Culturais têm futuros? E deverão tê-los? Comunicação e Cultura, Porto, n. 6, p. 17-51, 2008.

GUIMARÃES, Rodrigo Belinaso. Sociologia no ensino médio: cenários biopolíticos e biopotência em sala de aula. Tese (Doutorado) - Programa de Pós-Graduação em Educação da Universidade Federal do Rio Grande do Sul, Porto Alegre, 2013.

HALL, Stuart. A formação de um intelectual diaspórico: uma entrevista com Stuart Hall. In: SOVIK, Liv (Org.). Da diáspora: identidades e mediações culturais. Brasília/Belo Horizonte: UFMG/UNESCO, 2003.

HALL, Stuart. The spectacle of the 'other'. In: HALL, Stuart (Org.). Representation. cultural representations and signifying practices. London/Thousand Oaks/New Delhi: Sage/Open University, 1997.

HALL, Stuart; MELLINO, Miguel. La cultura y el poder: conversaciones sobre los cultural studies. Buenos Aires: Amorrortu, 2011.

JOHNSON, Richard. O que é afinal, estudos culturais? In: SILVA, Tomaz T. da (Org. e trad.). O que é, afinal, estudos culturais? Belo Horizonte: Autêntica, 1999. p. 7-131.

KARNOPP, Lodenir B.; KLEIN, Madalena; LUNARDILAZZARIN, Márcia L. (Org.). Cultura surda na contemporaneidade: negociações, intercorrências e provocações. Canoas: Editora da ULBRA, 2011.

KELLNER, Douglas. A cultura da mídia: Estudos Culturais identidade e política entre o moderno e o pós-moderno. Bauru: EDUSC, 2001.

KELLNER, Douglas. Lendo imagens criticamente: em direção a uma pedagogia pós-moderna. In: SILVA, Tomaz Tadeu da (Org.). Alienígenas na sala de aula: uma introdução aos Estudos Culturais em educação. 7. ed. Petrópolis: Vozes, 2008.

KRIEGER, Maria da G. T. Políticas públicas de inclusão moldando condutas e governando sujeitos. 2014. 115 f. Dissertação (Mestrado em Educação) - Faculdade de Educação, Universidade Luterana do Brasil, Canoas, 2014.

LARROSA, Jorge. Tecnologias do eu e educação. In: SILVA, Tomaz Tadeu da (Org.). O sujeito da educação: estudos foucaultianos. Petrópolis: Vozes, 1994, p. 35-86.

LEMOS, Sandra M. Programa Alfabetiza Rio Grande: a "importância de voltar a estudar" na produção textual de alfabetizandos adultos. 2008. 116 f. Dissertação (Mestrado em
Educação) - Faculdade de Educação, Universidade Federal do Rio Grande do Sul, Porto Alegre, 2008.

LINCK, Rosane Speggiorin. Hora do recreio! Processos de pertencimentos identitários juvenis nos tempos e espaços escolares. 2009. 145 f. Dissertação (Mestrado em Educação) Faculdade de Educação, Universidade Federal do Rio Grande do Sul, Porto Alegre, 2009.

LOCKMANN, Kamila. Inclusão escolar: saberes que operam para governar a população. 2010. 180 f. Dissertação (Mestrado em Educação) - Faculdade de Educação, Universidade Federal do Rio Grande do Sul, Porto Alegre, 2010.

LOPEZ, Danusa Mansur. O que pode ser tão interessante na escola quanto a hora do recreio? Em busca de práticas alternativas na escola contemporânea. 2010. 103 f. Dissertação (Mestrado em Educação) - Faculdade de Educação, Universidade Federal do Rio Grande do Sul, Porto Alegre, 2010.

MANSKE, George Saliba. Um currículo para a produção de lideranças juvenis na Associação Cristã de Moços de Porto Alegre. 2006. 209 f. Dissertação (Mestrado em Educação) Faculdade de Educação, Universidade Federal do Rio Grande do Sul, Porto Alegre, 2006.

MARQUES, Cíntia Bueno. Estou online! O imperativo da conexão reconfigurando sensibilidades nas relações de afeto entre sujeitos jovens contemporâneos. 2013. 145 f. Tese (Doutorado em Educação) - Faculdade de Educação, Universidade Federal do Rio Grande do Sul, Porto Alegre, 2013.

MATTELARD, Armand; NEVEU, Éric. Introdução aos estudos culturais. São Paulo: Parábola, 2004.

MELlO, Darlize Teixeira de. Provinha de leitura: mais uma "avaliação sob medida" do processo de alfabetização e letramento inicial? 2012. 402 f. Tese (Doutorado em Educação) - Faculdade de Educação, Universidade Federal do Rio Grande do Sul, Porto Alegre, 2012.

MENDES, Márcia Angélica. O mundo representado e a produção de identidades culturais em imagens de livros didáticos de inglês: uma análise. 2007. 122 f. Dissertação (Mestrado em Educação) - Faculdade de Educação, Universidade Luterana do Brasil, Canoas, 2007.

MOREIRA, Antônio Flávio Barbosa. Currículo e estudos culturais: tensões e desafios em torno das identidades. In: SILVEIRA, Rosa Maria Hessel (Org.). Cultura, poder e educação: um debate sobre Estudos Culturais em educação. 2. ed. Canoas: Editora ULBRA, 2011.

MULLER, Ana Solange. As campanhas de voluntariado na escola. (Dissertação de Mestrado) - Programa de PósGraduação em Educação da Universidade Luterana do Brasil, Canoas, 2008.

NELSON, Cary; TREICHLER, Paula; GROSSBERG, Laurence. Cultural studies. New York; London: Routledge, 1992.

NELSON, Cary; TREICHLER, Paula; GROSSBERG, Laurence. Estudos culturais: uma introdução. In: SILVA, Tomaz Tadeu (Org.). Alienígenas na sala de aula. Petrópolis: Vozes, 1995.

NOGUERA-RAMÍREZ, Carlos Ernesto. O governamento pedagógico: da sociedade do ensino para a sociedade da aprendizagem. Tese (Doutorado) - Programa de Pós-Graduação 
em Educação da Universidade Federal do Rio Grande do Sul, Porto Alegre, 2009.

OLIVEIRA. Teresinha Silva de. Olhares poderosos: o índio em livros didáticos e revistas. 2001. Dissertação (Mestrado em Educação) - Faculdade de Educação, Universidade Federal do Rio Grande do Sul, Porto Alegre, 2001.

PEREIRA, Angélica Silvana. Somos expressão, não subversão!!!: a gurizada punk em Porto Alegre. 2006. 163 f. Dissertação (Mestrado em Educação) - Faculdade de Educação, Universidade Federal do Rio Grande do Sul, Porto Alegre, 2006.

PEREIRA, Angélica Silvana. Domingo no parque: notas sobre a experiência de ser jovem na contemporaneidade. 2012. 253 f. Tese (Doutorado em Educação) - Faculdade de Educação, Universidade Federal do Rio Grande do Sul, Porto Alegre, 2012 .

PEREIRA, Angélica Silvana; GARBIN, Elisabete Maria. Práticas culturais juvenis (de)marcando corpos nas paisagens urbanas. In: KOBOLDT CAVALCANTE, Márcia H.; SOUZA, Rui Antonio de (Org.). Culturas juvenis: dinamizando a escola. Porto Alegre: Edipucrs, 2009. p. 89-98.

PINHEIRO, Claudia Gewehr. Pareceres descritivos: narrativas que a escola nos conta. 2006. 163 f. Dissertação (Mestrado em Educação) - Faculdade de Educação, Universidade Federal do Rio Grande do Sul, Porto Alegre, 2006.

PINHEIRO, Daiane. Produções surdas no YouTube: consumindo a cultura. In: KARNOPP, Lodenir; KLEIN, Madalena; LUNARDI-LAZZARIN, Márcia. (Org.). Cultura surda na contemporaneidade: negociações, intercorrências e provocações. Canoas: ULBRA, 2011.

PRATES, Camille Jacques. O Complexo W.I.T.C.H: acionando a magia para formar garotinhas nas redes do consumo. 2008. 194 f. Dissertação (Mestrado em Educação) - Faculdade de Educação, Universidade Luterana do Brasil, Canoas, 2008.

QUADROS, Marta Campos de. Tá ligado!? práticas de escuta de jovens urbanos contemporâneos e panoramas sonoros na metrópole uma pauta para a educação. 2011. $210 \mathrm{f}$. Tese (Doutorado em Educação) - Faculdade de Educação, Universidade Federal do Rio Grande do Sul, Porto Alegre, 2011 .

RATTO, Ana Lúcia Silva. Livros de ocorrência: disciplinamento, normalização e subjetivação. 2004. Tese (Doutorado em Educação) - Faculdade de Educação, Universidade Federal do Rio Grande do Sul, Porto Alegre, 2004.

ROSSI, Rossana Cassanta. Patrolando juventudes: o caderno Patrola ensinando jovens a consumir. 2007. Dissertação (Mestrado em Educação) - Faculdade de Educação, Universidade Federal do Rio Grande do Sul, Porto Alegre, 2007.

SANTOS, Cláudia Amaral dos. A invenção da infância generificada: a pedagogia da mídia impressa constituindo as identidades de gênero. 2004. 154 f. Dissertação (Mestrado em Educação) - Faculdade de Educação, Universidade Federal do Rio Grande do Sul, Porto Alegre, 2004.

SANTOS, Iolanda Universina Montano dos. Cuidar e curar para governar: as campanhas de saúde na escola. 2004. $216 \mathrm{f}$. Dissertação (Mestrado em Educação) - Faculdade de Educação, Universidade Federal do Rio Grande do Sul, Porto Alegre, 2004.
SANTOS, Lisandra. Juventudes contadas no jornal Mundo Jovem: modos de pensar o sujeito jovem contemporâneo. 2012. 107 f. Dissertação (Mestrado em Educação) - Faculdade de Educação, Universidade Federal do Rio Grande do Sul, Porto Alegre, 2012.

SANTOS, Lisiane G. Sons das tribos: compondo identidades juvenis em uma escola urbana de Porto Alegre. 2006. Dissertação (Mestrado em Educação) - Faculdade de Educação, Universidade Federal do Rio Grande do Sul, Porto Alegre, 2006.

SCHINEIDER. Suzana. O projeto-piloto de alfabetização do Rio Grande do Sul: um olhar de estranhamento sobre seus materiais didáticos. 2009. 149 f. Dissertação (Mestrado em Educação) - Faculdade de Educação, Universidade Federal do Rio Grande do Sul, Porto Alegre, 2009.

SCHULMAN, Norma. O Centre for Contemporary Cultural Studies da Universidade de Birmingham: uma história cultural. In: SILVA, Tomaz Tadeu (Org.). O que é, afinal, estudos culturais. Belo Horizonte: Autêntica, 1999.

SEVERO, Rita Cristine Basso Soares. As gurias normais do curso normal do Instituto de Educação de Porto Alegre. 2008. 103 f. Dissertação (Mestrado em Educação) - Faculdade de Educação, Universidade Federal do Rio Grande do Sul, Porto Alegre, 2008.

SILVA, Eloenes Lima da. A gente chega e se apropria do espaço! Graffiti e pichações demarcando espaços urbanos em Porto Alegre. 2010. 167 f. Dissertação (Mestrado em Educação) - Faculdade de Educação, Universidade Federal do Rio Grande do Sul, Porto Alegre, 2010a.

SILVA, Halan Kardeck Ferreira. Uma pedagogia cultural militante: representações e identidades do vaqueiro no Cinema Novo. 2010. Dissertação (Mestrado em Educação) - Faculdade de Educação, Universidade Luterana do Brasil, Canoas, 2010 b.

SILVA, Thais Coelho da. Juventude trans-viada: identidades marcadas invadem a rua. 2008. 103 f. Dissertação (Mestrado em Educação) - Faculdade de Educação, Universidade Federal do Rio Grande do Sul, Porto Alegre, 2008.

SILVA, Tomaz Tadeu da. Teoria cultural e educação: um vocabulário crítico. Belo Horizonte: Autêntica, 2000.

SILVEIRA, Rosa Maria Hessel (Org.). Estudos Culturais para professor@s. Canoas: Ed. da Ulbra, 2008.

SIMON, Roger. A pedagogia como uma tecnologia cultural. In: SILVA, Tomaz Tadeu (Org.). Alienígenas na sala de aula: uma introdução aos Estudos Culturais em educação. 7. ed. Petrópolis: Vozes, 2008.

SPERRHAKE, Renata. O saber estatístico como dizer verdadeiro sobre a alfabetização. 2013. 132 f. Dissertação (Mestrado em Educação) - Faculdade de Educação, Universidade Federal do Rio Grande do Sul, Porto Alegre, 2013.

STEINBERG, Shirley; KINCHELOE, Joe (Org.). Cultura infantil: a construção corporativa da infância. 2. ed. Rio de Janeiro: Civilização Brasileira, 2004.

STEINBERG, Shirley; KINCHELOE, Joe. Sem segredos: cultura infantil, saturação de informação e infância pósmoderna. In: STEINBERG, Shirley; KINCHELOE, Joe (Org.). Cultura infantil: a construção corporativa da infância. 2. ed. Rio de Janeiro: Civilização Brasileira, 2004. p. 9-52. 
STRASSBURGER, Viviane Maccari. "Como se ensina a ser velho/a" - na experiência teatral do Grupo Sem Teias. 2011. 123 f. Dissertação (Mestrado em Educação) - Faculdade de Educação, Universidade Luterana do Brasil, Canoas, 2011.

STRAUB, José Luis. Brincadeiras: práticas culturais de governo da criança. 2000. Dissertação (Mestrado em Educação) - Faculdade de Educação, Universidade Federal do Rio Grande do Sul, Porto Alegre, 2000.

THOMA, Adriana da Silva. O cinema e a flutuação das representações surdas: "que drama se desenrola neste filme? Depende da perspectiva..." 2002. 258 f. Tese (Doutorado em Educação) - Faculdade de Educação, Universidade Federal do Rio Grande do Sul, Porto Alegre, 2002.

TONINI, Ivaine Maria. Identidades capturadas: gênero, geração e etnia na hierarquia territorial dos livros didáticos de geografia. 2002. Tese (Doutorado em Educação) - Faculdade de Educação, Universidade Federal do Rio Grande do Sul, Porto Alegre, 2002.

TREND, David. Cultural pedagogy: art, education, politics. New York: Bergin \& Garvey, 1992.

TRINDADE, Iole Maria Faviero. A invenção de uma nova ordem para as cartilhas: ser maternal, nacional e mestra. Queres ler? 2001. 524 f. Tese (Doutorado em Educação) Faculdade de Educação, Universidade Federal do Rio Grande do Sul, Porto Alegre, 2001.

VARGAS, Juliana Ribeiro de. Meninas (mal) comportadas: posturas e estranhamentos em uma escola pública de periferia. 2008. 134 f. Dissertação (Mestrado em Educação) - Faculdade de Educação, Universidade Federal do Rio Grande do Sul, Porto Alegre, 2008.

WORTMANN, Maria Lúcia Castagna. [Re]inventando a educação a partir dos estudos culturais: notas sobre a articulação desses campos no ambiente universitário gaúcho. In: SARAIVA, Karla; MARCELLO, Fabiana de Amorim (Org.). Estudos Culturais e educação: desafios atuais. Canoas: Editora da Ulbra, 2012.

XAVIER, Maria Luisa Merino. Os incluídos na escola: o disciplinamento nos processos emancipatórios. 2003. $264 \mathrm{f}$. Tese (Doutorado em Educação) - Faculdade de Educação, Universidade Federal do Rio Grande do Sul, Porto Alegre, 2003.

\section{NOTAS}

1 O PPGEDU/UFRGS começou a funcionar em 1972, oferecendo o Curso de Mestrado em Educação, tendo sido credenciado em 1974 (Parecer no 657/74, do CFE). Posteriormente, em 1976, o Programa passou a oferecer o curso de Doutorado em Ciências Humanas - Educação, credenciado pelo Parecer 181/82 e recredenciado pelo Parecer 645/90. Fonte: $<$ http:// www.ufrgs.br/pos/>. Acesso em: 10 maio 2014.

2 A expressão "praticantes" tem sido adotada para designar os analistas culturais que atuam nesse campo.

3 Lidamos com o conceito de articulação a partir de Stuart Hall (1998), entendendo ser essa "uma forma de conexão [...] um acoplamento não necessário, não determinado, nem tampouco absoluto ou essencial para todas as circunstâncias" (p. 142)

4 Um maior detalhamento dos acontecimentos que caracterizaram este momento pode ser encontrado em Wortmann (2012), cf. Referências.

5 Entre os conferencistas, painelistas e debatedores das mesas do seminário estavam Tomaz Tadeu Silva e Guacira Lopes Louro (professores da Faculdade de Educação da UFRGS), Michael Apple (professor da Universidade de Wisconsin, USA), Mariano Narodowski (à época professor da Universidad Nacional de Quilmes, Argentina), Júlia Varela e Fernando Álvarez-Uría (ambos professores da Universidade Complutense de Madrid, Espanha), Pablo Gentili (professor da Universidade do Rio de Janeiro, Brasil) e Regina Leite Garcia (professora da Universidade Federal Fluminense, Brasil).

6 Estamos nos referindo aos anos de1994 a 1996.

7 Estes Seminários ocorriam nos finais de tarde das segundas-feiras e deles participavam professores e professoras da própria Faculdade de Educação, bem como de outras unidades da UFRGS e de outras universidades, que frequentavam os cursos de mestrado e doutorado do PPG/Educação à época.

8 A partir de agora utilizaremos EC para referir estudos culturais e ECE para estudos culturais em educação.

9 Este livro, organizado por Tomaz Tadeu da Silva e publicado pela editora Vozes em 1995, encontra-se em sua $10^{\text {a }}$ edição (2012), observando-se que o organizador é também o tradutor dos artigos que o compõem.

${ }^{10} \mathrm{O}$ título original do texto de Nelson, Treichler e Grossberg é Cultural studies. An introduction.

11 Trata-se da tradução do texto Post-marxism and cultural studies: a post-scrip, no qual a autora aborda as relações possíveis entre os EC e o pensamento crítico marxista.

12 As muitas histórias narradas sobre a emergência dos estudos culturais situam este Centro, na Universidade de Birmingham, como o seu ponto de irradiação mais importante, pelo menos nos anos iniciais.

${ }^{13}$ Levantamento preliminar (e talvez incompleto) indica que também produzem estudos nesta direção o Mestrado Interdisciplinar em Estudos Culturais Contemporâneos, da Fundação Mineira de Educação e Cultura (Universidade FUMEC/Minas Gerais) e a Universidade Federal da Paraíba (UFPB), que conta com a linha de pesquisa Estudos Culturais da Educação no Programa de Pós-Graduação em Educação. Na Universidade Estadual de Londrina (UEL), há um grupo de estudos que focaliza as relações entre os chamados estudos culturais da ciência e a Educação, e, na Universidade Federal de Santa Catarina (UFSC), há o Grupo Tecendo: educação ambiental e estudos culturais. Há, ainda, doutores e mestres com formação e pesquisas em estudos culturais atuando nas seguintes universidades brasileiras: Universidade Federal de Rio Grande (FURG), Universidade Federal do Rio Grande do Norte (UFRN), Universidade Federal de Pelotas (UFPEL), Universidade Federal de Santa Maria (UFSM), Universidade do Estado do Rio Grande do Sul (UERGS), Universidade Federal Fluminense (UFF), Universidade Federal da Grande Dourados (UFGD), Universidade do Estado de Mato Grosso (UNEMAT), Universidade do Estado do Amazonas (UEA), Universidade do Vale do Rio dos Sinos (UNISINOS), Universidade Feevale (FEEVALE), Faculdades Integradas São Judas Tadeu, Instituto Federal de Educação, Ciência e Tecnologia Sul-rio-grandense, Centro Universitário Metodista (IPA) e Universidade Católica de Brasília (UCB). Incluímos aqui também o GPEF/FEUSP (Grupo de Pesquisa em Educação Física da Faculdade de Educação da USP) que, segundo informação constante no parecer de um dos avaliadores do presente artigo, já tem dez anos de produção inspirada nos EC.

${ }^{14}$ Dados referentes ao período de dezembro de 1997 a julho de 2014.

${ }^{15}$ Levantamento realizado junto à Universidade Luterana do Brasil (ULBRA) indica já terem sido defendidas 186 dissertações de mestrado neste programa até julho de 2014.

${ }^{16}$ Ver <http://www.cnpq.br/documents/10157/186158/TabeladeAreasdo Conhecimento.pdf $>$.

${ }^{17}$ Alguns deles podem ser localizados em Costa (2002, 2010) e Silveira (2008). Conf. Referências.

${ }^{18}$ Contabilizaram-se, nesta IV edição do SBECE e I edição do SIECE, mais de seiscentas inscrições, que congregaram 124 instituições entre universidades nacionais e estrangeiras.

19 Thompson é Professor na Open University, Reino Unido, e Mato é coordenador do projeto de pesquisa "Diversidade Cultural, Interculturalidade e Educação Superior", do Instituto Internacional da UNESCO para Educação Superior na América Latina e Caribe (IESALC).

${ }^{20}$ Popkewitz é professor do Departamento de Currículo e Instrução da School of Education da Universidade de Wisconsin-Madison; Yúdice é professor de Estudos Latino-Americanos da Universidade de Miami, USA; Ramos do Ó é professor associado do Instituto de Educação da Universidade de Lisboa, Portugal; Gvirtz é professora da Universidade de San Andrés, Buenos Aires, Argentina, e Arfuch é professora da Faculdade de Ciências Sociais da Universidade de Buenos Aires, Argentina.

${ }^{21}$ Nóvoa é professor e ex-reitor da Universidade de Lisboa, Portugal, e Narodowski é professor da Universidade Torcuato Di Tella, Argentina 
22 Toby Miller é professor da Universidade da Califórnia, USA, e Eduardo Restrepo, da Universidade Javeriana de Bogotá, Colômbia.

${ }^{23}$ Rojas é professor da Universidade de Cauca, Colômbia, e Grimson é decano do Instituto de Altos Estudos Sociais da Universidade Nacional de San Martín.

${ }^{24}$ Entre os palestrantes brasileiros não vinculados às instituições promotoras do evento, destacam-se Antônio Flávio Barbosa Moreira, Susana Scramim, Margareth Rago, Ana Carolina Escosteguy e Sílvio Gallo (I SBECE); Maria Teresa Santos Cunha e Nilda Alves (II SBECE); Durval Muniz de Albuquerque Júnior, Rosália Duarte, Luis David Castiel (III SBECE); Ana Carolina Escosteguy, Paula Sibilia, Júlio Groppa Aquino, Leandro Belinaso Guimarães, Ieda Tucherman. Celso Cândido de Azambuja, Petronilha Beatriz Silva e Antônio Carlos Amorim (IV SBECE); André Lemos, Rildo Cosson, Saraí Schmidt, Mariângela Momo, Sylvio Gadelha, Maria Manuela Alves Garcia, Marlucy Paraíso, Maria Rita César, Walter Kohan e Madalena Klein (V SBECE).

${ }^{25}$ No caso da UFRGS, o levantamento compreendeu as dissertações e teses orientadas entre os anos de 1997 e 2013, pelos 15 professores que integram/integraram a linha de pesquisa no referido período. No caso dos professores que migraram para outras linhas de pesquisa, foram contabilizadas apenas as dissertações e teses orientadas enquanto durou a sua vinculação à linha.

${ }^{26}$ No caso da ULBRA, foram levantadas as dissertações orientadas entre os anos de 2002-2013, por 14 professores. No caso dos professores que migraram para outros Programas de Pós-Graduação foram contabilizadas, apenas, as orientações realizadas durante a sua vinculação ao PPG/ Educação da ULBRA.

${ }^{27}$ Em função dos limites do presente texto, estaremos referindo apenas alguns destes estudos.

${ }^{28}$ Alguns exemplos são Ratto (2004), Santos (2004b), Sperrhake (2013) e Lockmann (2010).

${ }^{29}$ Os estudos que integram a amostra da pesquisa de Costa e Andrade (2013) foram produzidos entre os anos de 2002 e 2011, em cinco programas de pós-graduação das regiões sudeste e sul, mais concentrados no Rio Grande do Sul.

${ }^{30} \mathrm{O}$ paradigma pós-fotográfico refere-se a imagens produzidas por computação gráfica.

${ }^{31}$ No PPGEducação da UFRGS, a grande maioria das dissertações e teses sob a inspiração dos EC que tomam a juventude como campo de estudos foi orientada pela Profa. Dra. Elisabete Garbin, como é o caso de Santos (2012), Linck (2010), Severo (2008), Silva (2008), Rossi (2007), Manske (2006), Santos (2004), Pereira (2004 e 2011) e Marques (2013). A esse respeito, ver ainda Pereira e Garbin (2009).

Artigo recebido em setembro 2014.

Aprovado em janeiro 2015. 